\title{
ANÁlise ECONÔMICA DO DIREITO DO TRABALHO E DA REFORMA TRABALHISTA \\ (LEI № 13.467/2017)
}

\author{
LUCIANA LUK-TAI YEUNG ${ }^{\dagger}$
}

\section{UM DOSSIÊ SOBRE ANÁlise ECONÔMICA Do DiREITO}

PAlaVRAs-ChAVE: Análise Econômica do Direito; Direito do Trabalho; Reforma Trabalhista; Microeconomia; Macroeconomia.

KEYWORDS: Economic Analysis of Law; Labor Law; Labor Reform; Microeconomy; Macroeconomy.

\footnotetext{
† Professora de Direito e Economia e Coordenadora do Núcleo de Instituições e Ambiente de Negócios (NIAN) do Insper.
} 


\section{SUMÁRIO:}

I. INTRODUÇã̃ .........................................................................................894

II. DIREITO E ECONOMIA ...........................................................................895

1. Princípios econômicos aplicados ao Direito...........................895

1.1. Escolha Racional .........................................................895

1.2. Tradeoffs e custos de oportunidade ..............................896

1.3. Incentivos ................................................................. 897

1.4. Comércio pode ser um jogo de "ganha-ganha"..........898

1.5. Mercados são melhores formas de organizer a atividade econômica .................................................899

1.6. Estado necessário para corrigir as falhas do Mercado899

1.7. Bem-estar medido por produtividade ...........................902

1.8. Teorema de Coase e Custos de Transação...................902

2. Análise Econômica do Direito do Trabalho...........................903

III. O CONTEXTO DO TRABALHO NO BRASIL E A CONSOLIDAÇÃO DAS

LEIS DO TRABALHO ...........................................................................906

1. A CLT e o mercado de trabalho brasileiro: trabalhadores premium $\mathrm{x}$ trabalhadores informais ...................................909

2. Efeitos microeconômicos.........................................................910

3. Efeitos macroeconômicos: alta propensão a consumir, baixa propensão a poupar .....911

IV. ANÁlise ECONÔMICA dA REFORMA TrabalHISTA: ALGUNS PONTOS PARA ANÁLISE .................................................914

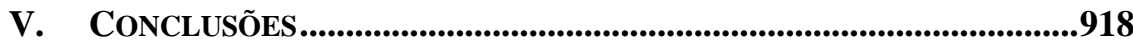

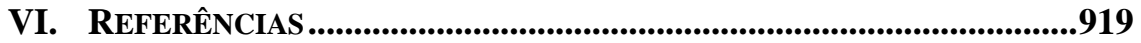




\section{TABLE OF CONTENTS:}

I. INTRODUCTION .....................................................................................894

II. LAW AND ECONOMICS ..............................................................895

1. Economic principles applied in Law ....................................895

1.1. Rational Choice ......................................................895

1.2. Tradeoffs e opportunities costs ..................................896

1.3. Incentives ...........................................................8. 897

1.4. Commerce can be a win-win game .............................898

1.5. Markets are the best way of organize the economic activity .................................................................... 899

1.6. Necessary State to correct the market failures ...........899

1.7. Welfare measured by productivity ............................902

1.8. The Coase Theorem and Transaction Costs ...............902

2. Economic Analysis of Labor Law ......................................903

III. THE CONTEXT OF LABOR IN BRAZIL AND THE CONSOLIDAÇÃO DAS LEIS DO TRABALHO ........................................................906

1. The CLT and the brazilian labor market: premium workers

$x$ informal workers............................................................909

2. Microeconomic effects........................................................910

3. Macroeconomic effects:

high consumer propensity, low propensity to save .............911

IV. ECONOMIC ANALYSIS OF THE LABOR REFORM:

SOME POINTS OF ANALYSIS .......................................................914

V. CONCLUSIONS ..........................................................................918

VI. REFERENCES ..................................................................................9919 


\section{INTRODUÇÃO}

No fim do ano de 2017, em meio a conturbada crise política e em plena recuperação da economia, o país passava pelo o que, para alguns, seria talvez o início de uma nova era nas relações do trabalho. Sindicalistas e outros grupos de interesses trabalhistas, por sua vez, temiam pelo pior: reversão de conquistas das últimas décadas, precarização das condições de trabalho, fim da proteção normativa à classe trabalhadora, volta à exploração pelo grande capital, e também, dificuldade de sobrevivência do movimento trabalhista causado, entre outras coisas, pelo fim da contribuição sindical obrigatória.

De um lado, um otimismo talvez excessivo; do outro, uma preocupação exagerada - típicos de momentos de transição, de mudanças de status quo, como este que prevaleceu pela sociedade brasileira por mais de sete décadas, e na verdade, desde que o Brasil não-agrário se entende como nação.

O objetivo deste ensaio é usar a lente da análise econômica para observar o Direito do Trabalho brasileiro e, sobretudo, os pontos da chamada Reforma Trabalhista (Lei № 13.467/2017). A análise econômica se diferencia da análise dogmática e doutrinária, mais tradicionais do Direito, pois: (i) coloca, a todo momento, suas análises a teste de falseabilidade por fatos e evidências das observações do mundo real, como preconizam os filósofos das ciências, como Karl Popper ${ }^{1}$; (ii) tenta isentar-se de roupagem ideológica, no intuito de, partindo de premissas (hipóteses) testáveis, coletar observações empíricas em quantidade e/ou representatividade significativa do objeto que se quer estudar, para só assim, gerar conclusões; (iii) tem como intenção gerar previsões de eventos futuros com base em observações objetivas de fatos do passado (como mostrado no item anterior); (iv) não sobrevive a argumentos argumentum ad verecundiam, pois pode ser refutada caso a metodologia empregada, ou os dados usados para se chegar a determinada conclusão não se sustentarem pela observação de outros autores. Desta forma, a análise econômica pretende gerar conhecimento e conclusões que sejam mais objetivas, de sustentação sólida perante fatos e dados coletados por diferentes autores ao longo do tempo e do espaço, isenta de opiniões e valores pessoais, e com grande poder preditivo do futuro.

${ }^{1}$ Cf. POPPER, Karl. A Lógica da Pesquisa Científica. 11aㅡ ed. Trad. Leonidas

Hegenberg; Octanny Silveira da Mota. São Paulo, SP: Editora Cultrix, 2004. 


\section{DiREITO E ECONOMIA}

\section{Princípios econômicos aplicados ao Direito}

A análise econômica constitui-se em um instrumental de observação da realidade social; na verdade, trata-se de um poderoso instrumental, pois tem capacidade preditiva do comportamento e da organização dos indivíduos em sociedade. Com base nas previsões derivadas da análise econômica, é possível chegar-se à criação de normas (legais ou não), que gerem resultados mais ou menos desejáveis para um planejador central, seja ele o líder de uma organização ou mesmo de um Estado. Para entender essa dinâmica é preciso voltar à base da ciência econômica, o que efetivamente a distingue e define.

Ao contrário do que o senso comum adota, o objeto de estudo da ciência econômica não é o dinheiro ou a economia (no sentido de mercados de compra e venda), mas as consequências das decisões ou escolha dos indivíduos, sob quaisquer aspectos: escolhas sobre aquisições materiais sim, mas também escolhas de alocação de tempo, de planejamento de carreira, de investimento em escolaridade, de carreira, de constituição de família, e, por que não, de cometer ou não atos ilícitos. Todas essas decisões, o que leva os indivíduos a optarem pela alternativa " $\mathrm{A}$ " ou " $\mathrm{B}$ ", e as implicações destas decisões são temas cruciais para a análise da ciência econômica e, neste sentido, ela é um instrumento essencial para se analisar também os efeitos das normas legais. ${ }^{2}$

\subsection{Escolha Racional}

A ciência econômica parte do pressuposto de que os seres humanos são racionais e que, portanto, indivíduos em sociedade tomam decisões baseadas na racionalidade. No entanto, este conceito não remete somente a pessoas com alta capacidade cognitiva, grau de instrução, ou conhecimento de ciências sofisticadas. Nem mesmo é necessário que o indivíduo tenha alguma escolaridade para ser capaz de tomar decisões racionais. Será racional qualquer escolha feita por alguém que deseja alguma coisa (por utilidade, necessidade, ou prazer), e que sabe que, para se obter esse coisa, é preciso dispender algum esforço monetário, temporal ou de trabalho, etc. Um exemplo seria um morador de rua, analfabeto e sem emprego, que deseja comer. Ele sabe que para conseguir

${ }^{2}$ Cf. FRIEDMAN, David. Law's Order: What Economics has to do with Law and why it Matters. Princeton, NJ: Princeton University Press, 2001, p. 8. 
a comida deverá trabalhar, esmolar ou furtar - entre outras opções eventualmente disponíveis a ele. Se ele efetivamente escolhe uma dessas ações para conseguir a comida, levando-se em conta suas possibilidades, oportunidades ou habilidades pessoais, age de maneira racional. Então, todas as escolhas, por mais instantâneas que sejam feitas, ou ao contrário, por mais meticulosamente planejadas que tenham sido, que passem por esta avaliação (explícita ou implícita) de custos e benefícios, é uma escolha racional.

O conceito de escolha racional pode ser diretamente aplicado ao Direito. Por exemplo, a decisão de um indivíduo de violar ou não as regras de trânsito - beber antes de conduzir o carro, ou igualmente, atravessar o farol vermelho - sabendo-se de que há benefícios advindos desta decisão (ter o prazer da bebida, ou chegar mais rápido ao seu destino, respectivamente), mas também custos (a probabilidade de ser pego em uma blitz e levar a multa). Este é um claro exemplo de como princípios da ciência econômica podem se constituir em instrumentos essenciais para a análise dos efeitos de normas legais.

\subsection{Tradeoffs e custos de oportunidade}

Outro princípio sobre a qual resta a ciência econômica é o conceito de escassez, ou melhor, de finitude de todos os recursos do planeta. E os dois recursos mais afetados pela finitude são os recursos monetários (dinheiro) e o tempo. Por causa disso, toda e qualquer escolha racional implica em tradeoffs: para fazer algo, precisa-se necessariamente abrir mão de outra coisa, porque não há dinheiro ou tempo para tudo. Se o tempo fosse infinito, nosso morador de rua (conforme exemplo acima) poderia trabalhar, esmolar e furtar ao mesmo tempo, sem ter que fazer escolha por uma única atividade. Mais, se o dinheiro fosse infinito, ele poderia comer, alugar uma casa, e fazer tudo o que quisesse, deixando até mesmo a necessidade de morar na rua. Dado que tempo e dinheiro para ele são finitos, ele precisa escolher uma atividade para conseguir comer.

$\mathrm{O}$ mesmo acontece com outras escolhas. Se o motorista exemplificado acima tivesse tempo ilimitado, não precisaria correr e escolher atravessar o farol vermelho. Em exemplos mais tradicionais da ciência econômica, se um consumidor tivesse dinheiro infinito, poderia comprar tudo que existe no mundo, e não teria que fazer escolha alguma. No entanto, mesmo o mais rico dos seres humanos tem limitação de recursos e, sobretudo, de tempo. Por causa disso, escolhas devem ser feitas, e sempre algo deverá ser deixado de lado ou preterido. Esta escolha preterida trará outro importante conceito econômico: o de custo de oportunidade. Custo de 
oportunidade é uma medida do valor daquilo que se deixou de ser escolhido, mais precisamente, da segunda melhor escolha. Então, se um consumidor tem 100 reais, deixa de consumir várias coisas para comprar uma roupa, e se a segunda melhor alternativa para ele(a) fosse ir a um restaurante, o custo de oportunidade de comprar a roupa é a ida ao restaurante. Dado que todos os recursos são limitados, toda escolha racional implica em tradeoffs, e geram custo de oportunidade.

\subsection{Incentivos}

Indivíduos que fazem escolhas racionais reagem a incentivos. Continuando o exemplo tradicional do consumidor decidindo como gastar seus 100 reais, caso haja uma redução no preço do restaurante, isso poderá motiva-lo(a) a trocar a compra da roupa pela ida ao restaurante. Os preços, então, constituem-se nos maiores incentivos com os quais consumidores irão se deparar no mercado.

No entanto, talvez um entendimento mais interessante sobre o conceito de incentivos aplique-se justamente à análise econômica do Direito. No mundo real, consumidores e empresas ofertantes não se deparam apenas com incentivos monetários, de preços. Por exemplo, mesmo que o preço da bebida alcoólica se tornasse muito baixo, determinados consumidores podem escolher por não consumi-la, pois eles terão que conduzir o automóvel logo em seguida. Ou seja, o incentivo que atuou na decisão de não consumir o álcool foi um incentivo legal. Da mesma maneira, as empresas não reagem apenas aos incentivos criados pelos preços. No caso delas, quanto maior o preço, normalmente elas teriam mais incentivos para vender. No entanto, mesmo a um preço muito alto, bares e restaurantes podem optar por não vender a bebida alcóolica, caso o potencial comprador seja um menor de idade, pois a lei assim proíbe este tipo de venda. Mais uma vez, o incentivo em ação não são preços, mas normas legais.

Na verdade, nas economias e nas sociedades modernas, grande parte dos incentivos colocados aos indivíduos e às empresas é de natureza normativa, legal ou institucional. Não basta reagir aos preços e às quantidades de mercado, é preciso agir de acordo com as leis, e reagir a elas. Então, os grandes incentivos colocados são também desta natureza. 


\subsection{Comércio pode ser um jogo de "ganha-ganha"}

Um dos primeiros proponentes da ideia de que o comércio (ou as trocas de maneira geral) gera resultados que são melhores foi Adam Smith, na mesma obra que se tornou o marco do nascimento da Ciência Econômica. Smith mostrava como um ferreiro, ao se especializar na produção de pregos acaba produzindo muito mais se tivesse que fazer outras coisas também. E [é] a grande multiplicação das produções de todos os diversos ofícios - multiplicação essa decorrente da divisão do trabalho - que gera, em uma sociedade bem dirigida, aquela riqueza universal (...). Cada trabalhador tem para vender uma grande quantidade do seu próprio trabalho, além daquela de que ele mesmo necessita. ${ }^{3}$ Com este aumento na produção, poderiam fazer trocas dos excedentes um com outro, e alcançar níveis de consumo e de bem estar mais alto, impossível de ser alcançado caso tivessem que, cada um, produzir todos os bens que precisassem para sobreviver. Pouco tempo depois, David Ricardo, outro fundador da Ciência Econômica, extrapolou o exemplo para os países. ${ }^{4}$ Em seu exemplo real, Inglaterra e Portugal - um especializando-se na produção de tecidos, e o outro na produção de vinhos - seriam capazes de consumir quantidades destes dois tipos de bens impossíveis de serem alcançados caso cada um se fechasse em si mesmo, tendo que produzir ambos. A ideia vem do conceito do vantagens competitivas: nenhum país, nenhuma pessoa, nenhuma empresa, por mais moderno e avançado que seja, tem vantagem competitiva na produção de todos os bens. Cada um irá, portanto, se especializar naquilo que tem mais vantagens em comparação aos outros (é possível que tenha vantagem absoluta, mas na decisão de trocas, não é este o conceito que importa ${ }^{5}$. Assim, em condições normais, na ausência de falhas de mercado (ver subseção VI abaixo), as trocas ou o comércio será benéfico para as partes envolvidas, constituindo-se em casos de ganha-ganha. A lógica por trás vem da possibilidade de alcançar maiores níveis de produção quando há especialização do trabalho, o que criaria excedentes que seriam trocados no comércio.

${ }^{3}$ Cf. SMITH, Adam. A Riqueza das Nações: Investigação sobre sua Natureza e suas Causas, Volume I. Trad. Luiz João Baraúna. São Paulo, SP: Nova Cultural, 1996, p. 70. ${ }^{4}$ Cf. RICARDO, David. Princípios de Economia Política e Tributação. Trad. Paulo Henrique Ribeiro Sandroni. São Paulo, SP: Nova Cultural, 1996, cap. VII. ${ }^{5}$ Cf. MANKIW, Gregory. Princípios de Microeconomia. 6 ${ }^{\underline{a}}$ ed. Trad. Allan Vidigal Hastings; Elisete Paes Lima; Ez2 Translate. São Paulo, SP: Cengage Learning, 2014. 


\subsection{Mercados são melhores formas de organizer a atividade econômica}

Por conta do que foi descrito no item anterior, em um nível agregado, onde os diversos agentes se especializam e vão ao mercado para realizar trocas de seus respectivos excedentes, é gerado um nível geral de bemestar maior. A economia em concorrência - onde os indivíduos, firmas e outras organizações são livres e autônomos para se especializarem naquelas tarefas e atividades nas quais têm vantagem competitiva alcança o equilíbrio (situação de estabilidade e segurança) e também o melhor resultado possível, dadas as dotações iniciais de recursos préexistentes. Este é o conhecido Primeiro Teorema Fundamental do BemEstar, derivado analiticamente (matematicamente) dos resultados de equilíbrio de mercados: uma economia em concorrência perfeita, onde as empresas tomam decisões racionais de maneira independente, gera um resultado agregado que é socialmente eficiente, ou seja, que maximiza o bem-estar social. ${ }^{6}$

E é conforme os resultados previstos pelo Primeiro Teorema Fundamental do Bem Estar (e também com base em observações empíricas do mundo real) que a Ciência Econômica defende a manutenção da liberdade econômica das empresas e dos indivíduos: nenhum resultado é possivelmente melhor do que o de livres mercados em termos de eficiência, que é o termo na economia para bem-estar social. No entanto, isso pode não ser verdade quando existem falhas de mercado.

\subsection{Estado necessário para corrigir as falhas do Mercado}

Apesar de o nome remeter a situações excepcionais, as falhas de mercado podem ser parte natural deste. Caso não fosse assim, o Direito não teria importância para a Economia, pois são justamente nas situações das falhas de mercado que será necessária a criação de regras normativas - normalmente executada pelo Estado - para corrigir aquelas primeiras. Em outras palavras, para a Economia, o Direito, as normas e as regras existem para corrigir as falhas de mercado. Vejamos algumas delas.

Externalidades: Existem diversas situações em que um agente (indivíduo ou empresa, por exemplo), atuando de maneira independente e autônoma, tomando decisões que a elas são racionais, acaba gerando benefícios inesperados e não intencionais a outros, ou seja, externalidades positivas. Por outro lado, também existem diversas situações em que

${ }^{6}$ Cf. MAS-COLELL, Andreu; WHINSTON, Michael; GREEN, Jerry. Microeconomic Theory. New York, NY: Oxford University Press, 1995, p. 150.

3 JOURNAL OF INSTITUTIONAL STUDIES 2 (2017) 
agentes independentes, tomando decisões racionais para si, acabam gerando custos para os outros, ou seja, as externalidades negativas. $\mathrm{O}$ exemplo mais clássico de externalidade positiva é o de uma casa que decide embelezar seu jardim que dá para a rua, ou que contrata uma segurança particular. Quando o dono da casa decide assim fazer para satisfazer a uma escolha racional própria, ele acaba gerando benefícios para seus vizinhos, por tornar toda a rua mais bonita ou mais segura. Já o exemplo clássico de externalidade negativa é o da poluição: a fábrica, tomando uma decisão racional de maximizar seu lucro, produz bens na sua planta; mas o efeito colateral disso para o restante da sociedade é ter que arcar com os custos da poluição causada por ela.

Assim como nos outros casos, esse conceito econômico pode ser diretamente aplicado ao mundo do Direito. Como exemplo de externalidades positivas, podemos pensar no caso de uma empresa que oferece treinamento para seus funcionários. Este treinamento, se for de habilidades gerais, será benéfico não somente para ela como empregadora, como também será bom para os funcionários, e até mesmo o restante da sociedade, por poder contar agora com mão de obra de melhor qualidade. No caso de externalidade negativa, também aplicado a um caso de Direito do Trabalho, temos como exemplo quando uma empresa não investe em ambientes seguros e salubres, com o intuito de economizar custos. Isso pode ser uma decisão racional para ela, mas gera doenças e outros riscos para o trabalhador e também para o serviço de saúde, que deverá ser eventualmente acionado para tratar o trabalhador quando este vier a ficar doente.

Assimetrias de Informação: No mundo moderno não deve haver falha de mercado mais comum e custosa do que as assimetrias de informação. O ser humano tem capacidade cognitiva limitada, não tem capacidade de prever o que ocorrerá com ele, com o mundo ou o universo em qualquer momento do futuro. Esta limitação leva ao resultado de que a humanidade sempre trabalhará e atuará sob a condição de informação imperfeita. No entanto, a imperfeição da informação - dado que atinge a todos indistintamente - não é o maior problema. O problema é maior quando partes que se relacionam têm acesso diferenciado a informações relevantes, ou seja, a informação é assimétrica, ou desigual, entre as partes (a-simétrico $=$ não simétrico, não igual). Nesses casos, claramente, quem tem maior acesso à informação terá privilégio em detrimento da outra parte. Isso, além de ser injusto (na perspectiva jurídica), é ineficiente (na perspectiva econômica). A grande questão é que as assimetrias de informação são muito comuns nas relações contratuais e nas relações entre duas ou mais partes; elas são comuns nas relações humanas e 
pessoais (pessoas naturais ou jurídicas). Para resolver este problema há que se recorrer à intervenção estatal, via garantia de contratos, via regulação de conduta, ou exigência de fornecimento de informações relevantes à relação - todas mediante ameaça de algum tipo de sanção legal.

Monopólios e Monopsônios: O conceito de monopólio é bastante difundido e provavelmente conhecido pela imensa maioria das pessoas: é monopolista aquela pessoa ou empresa que é o único vendedor de um serviço ou um produto. Ao contrário do que acredita o senso comum, o monopolista não pode vender ao preço que quiser (porque se o preço aumenta, os clientes podem simplesmente deixar de comprar seu produto, e substituir por algum substituto imperfeito, pois ninguém é obrigado a comprar nada que seu orçamento não permite; com isso, o monopolista poderá perder muitos clientes e receita). No entanto, é verdade que o monopolista detém um grande poder de mercado, e um grande poder de barganha frente a seus consumidores - muito maior do que acontece em situações de concorrência. Claramente, permitir o monopolista atuar livremente, sem nenhum tipo de regulação, não é a melhor situação para a economia como um todo, ou seja, a eficiência não será atingida. A regulação estatal será necessária, e não é coincidência que os setores onde se encontram os monopólios naturais, são justamente aqueles mais regulados na economia (por exemplo, setor de produção e distribuição de eletricidade, de petróleo, setor de telecomunicações, etc).

Um conceito menos conhecido, mas igualmente importante, é o de monopsônio: uma pessoa ou empresa que é o único comprador em um determinado local. Um exemplo clássico seria uma grande montadora de automóveis em uma determinada região geográfica. Todas as empresas metalúrgicas ao redor dela terão esta montadora como sua principal ou única cliente. Novamente, esta montadora terá grande poder de mercado e grande poder de barganha, porém nesta situação, perante seus fornecedores e ofertantes. Aplicado ao Direito do Trabalho, poderíamos ter como exemplo de monopsonista uma grande empresa, que fosse a principal ou única contratante de mão de obra em uma determinada região. Se ela é a única empregadora, claramente tem muito mais poder de barganha perante seus trabalhadores e potenciais trabalhadores. Assim como no caso de monopólio, a intervenção estatal será necessária para resolver a falha de mercado gerada pelo monopsônio. Somente com a atuação do Estado será possível garantir o máximo de bem-estar possível nessa situação, ou seja, a eficiência.

Como visto, em todas as situações em que existem falhas de mercado, os agentes deixados por si sós, funcionando livremente no mercado, não 
alcançarão o melhor resultado econômico, ou seja, não conseguirão alcançar a eficiência. A ciência econômica é clara: sempre que existirem falhas de mercado, a atuação do Estado será necessária para restaurar o equilíbrio e a maximização de bem-estar, ou seja, para garantir a eficiência.

\subsection{Bem-estar medido por produtividade}

Toda ciência tem seu referencial de resultado positivo e desejável, ou seja, seu ideal. No caso da ciência econômica, o ideal é a maximização da riqueza produzida; assim, a capacidade de uma pessoa, uma empresa, ou um país, de produzir bens materiais é a medida de sua produtividade. Assim sendo, o aumento da produtividade é o objetivo do desenvolvimento humano e social; por exemplo, o aumento da escolaridade, da capacidade técnica de pessoas e fábricas é voltado para o aumento de suas respectivas produtividades. Isso não quer dizer que a análise econômica desconsidera outros tipos de bem-estar, e que se importe somente por aquele derivado de bens materiais, mas apenas de que este último é a medida adotada como padrão de referência. Também, é pouco contestável hoje em dia que qualquer pessoa ou nação, para alcançar minimamente um nível de conforto e bem-estar, precisa ter bens materiais. A saciedade material não é condição suficiente, mas é certamente a primeira condição necessária para que alguém tenha uma vida satisfatória. Por este motivo, a unidade de medida para comparar países é a sua produtividade, por exemplo, o PIB (o Produto Interno Bruto produzido neste país) ou o PIB per capita. Mesmo que a Organização das Nações Unidas (ONU) tenha começado a adotar outras medidas de bemestar humano e qualidade de vida, como o IDH (o Índice de Desenvolvimento Humano), percebe-se que existe uma clara e forte correlação entre este indicador e outros indicadores de produtividade material, como o PIB per capita. Da mesma maneira, costuma-se medir a modernidade e o avanço de uma empresa ou um setor econômico por seu grau de produtividade e a evolução deste ao longo do tempo.

\subsection{Teorema de Coase e Custos de Transação}

O Teorema de Coase representa a concretização dos resultados de observações empíricas do economista Ronald Coase, fundador da Análise 
Econômica do Direito ${ }^{7}$, como bem descrito em seu artigo de $1960 .{ }^{8}$ Ele percebeu que, em situações onde os custos de transação são baixos, os agentes (indivíduos e/ou empresas) conseguem negociar de maneira relativamente cooperativa, e os resultados derivados dessas negociações serão os melhores, ou seja, maximizam os benefícios das partes envolvidas (ou seja, são eficientes). Nesses casos, não interessa qual é a determinação legal: mesmo que haja direitos garantidos, se valer a pena, os agentes transacionarão esses direitos. Por outro lado, caso haja custos transacionais significativos, a negociação privada terá sérios obstáculos para acontecer, e a lei (por exemplo, legislação, regulação, decisões judiciais, etc.) terá que atuar e impactará de maneira determinante no resultado econômico. A questão é que há diversas situações no mundo real em que a presença de tais custos de transação é significativa; essas são causadas não somente mas também pelas falhas de mercado discutidas no item (vi) acima. Como vimos, quando isso acontece, o Estado precisa intervir para garantir a eficiência.

Veremos que o Teorema de Coase terá um papel primordial no entendimento de relações contratuais, como a relação do trabalho entre empregador e empregado. Ele, por ser resultado de observações empíricas (e não meramente da autoridade de seu autor), fornecerá um guia objetivo de como o Estado deveria intervir a relação contratual trabalhista, caso o objetivo seja de maximizar o bem-estar social. Além disso, como bom instrumento econômico, ele será capaz de fazer previsões do que ocorrerá na economia em determinadas circunstâncias (altos ou baixos custos de transação) e, com base nisso, será muito útil para recomendar ações e decisões de políticas públicas de maneira eficaz e eficiente (por exemplo, maior ou menor intervenção, dados os fatores observações na prática).

\section{Análise Econômica do Direito do Trabalho}

Tendo em mente os princípios econômicos aplicáveis ao Direito, é possível debruçarmos sobre o objeto específico de nosso estudo neste artigo, a Análise Econômica do Direito do Trabalho. O que a distingue ou a torna peculiar de uma análise econômica do direito qualquer?

${ }^{7} \mathrm{O}$ termo foi cunhado pelo também economista George Stigler, cf. McCLOSKEY, Deirdre. Others Things Equal: The so-called Coase Theorem. Eastern Economic Journal, Vol. 24, 3, 1998, p. 367-371.

${ }^{8}$ Cf. COASE, Ronald. The Problem of Social Cost. Journal of Law and Economics, Vol. 3, 1, 1960, p. 1-44. 
O estudo das relações do trabalho tem sido bastante dividido. ${ }^{9}$ Dada a sua complexidade e essencialidade para as sociedades humanas é natural esperar que seu estudo tenha perspectivas múltiplas. No entanto, ter perspectiva múltipla não necessariamente implicaria perspectivas divididas - que parece ser o caso do estudo do trabalho. Reduzindo um pouco a análise aqui posta, podemos dizer que, de um lado, existe a Economia - e especificamente a Economia do Trabalho. Ela tem se focado principalmente com a análise dos benefícios dos jogadores. A abordagem econômica está preocupada com a análise do nível do emprego, rendimentos e benefícios dos trabalhadores (de curto e de longo prazo), pensões, etc. Os modelos econômicos ainda estudam os impactos sobre a produtividade, os lucros, a flexibilidade dos empregadores. Essa perspectiva vê trabalhadores e empregadores como se as únicas coisas que esses atores perseguissem no campo trabalhista fossem benefícios econômicos e materiais, e que a única relação é de vendedores e compradores. Este é o quadro básico da economia do trabalho: um mercado no qual a demanda (trabalhadores) e a oferta (empregadores) interagem.

Por outro lado, existe uma gama de ciências sociais que estudam as relações trabalhistas com uma perspectiva muito diferente. Dentro deste segundo grupo está o Direito, que não veem empregadores e trabalhadores em uma relação de vendedor versus comprador. Em vez disso, o Direito (e também a Sociologia) vê no trabalho uma relação naturalmente antagônica. O modelo de capital versus mão-de-obra é o eixo dessa análise, e todos os resultados dela derivam. Especificamente no caso do Direito do Trabalho, o objetivo é de derivar regras que suavizem esse conflito (sempre que possível) ou que equilibrem as forças opostas - normalmente protegendo a parte mais fraca, ou seja, os trabalhadores. Esses estudiosos consideram o locus do trabalho como um campo de batalha, em que as relações são permanentemente conflituosas. É como se o confronto diário fosse o único fenômeno acontecendo entre esses atores em seus encontros diários no local de trabalho. Obviamente ambas as abordagens são limitadas e insuficientes.

A Análise Econômica do Direito do Trabalho tenta considerar ambos os lados da visão, e ainda complementar com mais. Ela incorpora características do modelo econômico de demanda e oferta de mão-deobra e, como uma boa análise econômica, reconhece que trabalhadores e empregadores enfrentam vários tipos de incentivos e restrições que

${ }_{9}$ Cf. YEUNG, Luciana. Economic Analysis of Labor Law. In: Alain Marciano; Giovanni Battista Ramello (eds.). Encyclopedia of Law and Economics. New York, NY: Springer, 2017. 
afetam sua tomada de decisão. No entanto, diferentemente da análise econômica pura, também dá importância significativa à formulação, aplicação e execução de regras - contratuais ou regulatórias - na área trabalhista. Reconhece que a relação entre empregadores e trabalhadores não é apenas de vendedor versus comprador, e que o trabalho não é uma simples mercadoria, ou uma mercadoria simples. As relações humanas e as relações de poder são muito importantes aqui. Embora a Análise Econômica do Direito a priori adote o modelo econômico do mercado de trabalho, ela reconhece que este é um mercado especial, em que as falhas são a norma: as informações são assimétricas (tanto do lado do trabalhador, quanto do lado do empregador), existem externalidades, as negociações e os poderes de barganha são desiguais, existem monopólios e monopsônios, etc. Com tudo isso, há fontes de altos custos de transação e, como a abordagem normativa do Teorema de Coase nos diz, nessas circunstâncias, as regras legais têm um papel importante na determinação dos níveis de eficiência. ${ }^{10}$ Em outras palavras, neste mercado, as instituições importam, e importam muito.

A Análise Econômica do Direito entende, então, que as relações de trabalho baseiam-se em relações contratuais, (geralmente) de longo prazo, caracterizadas por altos níveis de incertezas e informações assimétricas. Diferente do que acontece em alguns outros mercados, o poder de barganha aqui é inerentemente desigual entre ofertantes (ou seja, trabalhadores) e demandantes (ou seja, empregadores). Também monopólios e monopsônios ocorrem com frequência, como por exemplo, nos casos de sindicatos - como monopolistas da oferta de mão de obra e os grandes empregadores - como monopsonistas. Isso quer dizer que as falhas de mercado podem não ser exceções neste caso. A teoria econômica diz que, nestes casos, a regulação via intervenção estatal é necessária para resolver essas falhas. Um agente terceiro - geralmente o Estado - deve intervir, caso contrário, o maior nível de bem-estar social (ou seja, a eficiência) não será alcançado, e riqueza nacional será perdida. O problema é que uma má intervenção pode ser pior do que a ausência total de intervenção. Muitas vezes, a Análise Econômica do Direito do Trabalho nos mostrará que o problema reside justamente aqui.

Pode-se dizer, assim, que o objetivo do Direito do Trabalho nas democracias modernas deveria ser o de fornecer instituições sólidas que equilibrassem informações, poder de barganha e relações contratuais. Ao mesmo tempo, deveriam promover o crescimento econômico, promovendo o aumento da eficiência das empresas para que a criação e

${ }^{10}$ Cf. COASE, Ronald. The Problem of Social Cost. Journal of Law and

Economics, Vol. 3, 1, 1960, p. 1-44.

3 JOURNAL OF INSTITUTIONAL STUDIES 2 (2017) 
manutenção das oportunidades de emprego fossem sustentáveis ao longo do tempo. Se as empresas empregadoras não tiverem benefícios ou incentivos, não irão contratar, e nem mesmo a lei poderá obriga-las a fazer isso. Assim, a criação de regras que regulassem e equilibrassem o mercado de trabalho deve envolver os poderes Executivo, Legislativo e também o Judiciário.

No entanto, parece que muitos países falharam nesta tarefa, quer pendendo demais para um lado - ou seja, intervenção excessiva ou ruim do mercado de trabalho, dificultando o potencial crescimento econômico (por exemplo, países da América Latina, Espanha, Itália, etc.) - quer pendendo demais para o outro lado: com ausência ou falta de regulação do trabalho, levando ao baixo nível de bem-estar, condições precárias de trabalho ou desigualdade (por exemplo, países em desenvolvimento da Ásia e, em até certo ponto, EUA, em comparação com outros países industrializados). Em certo sentido, isso reflete uma visão unilateral do trabalho, seja excessivamente liberal/desregulamentadora, ou excessivamente reguladora, com demasiada proteção aos considerados hipossuficientes. A Análise Econômica do Direito pretende seguir um caminho de equilíbrio entre essas duas visões da regulamentação do trabalho.

\section{O CONTEXTO DO TRABALHO NO BRASIL E A CONSOLIDAÇÃO DAS LEIS DO TRABALHO}

Mais de setenta anos depois de sua criação, a Consolidação das Leis do Trabalho (CLT) continua sendo a base que rege o trabalho privado formal no Brasil. Não é muito difícil perceber que: (i) a legislação trabalhista original está ultrapassada e inadequada para as realidades econômicas, políticas e sociais do Brasil de hoje (para mantê-la minimamente atualizada é preciso recorrer às centenas de emendas, portarias, leis ordinárias, etc.); (ii) a legislação trabalhista, em seu conjunto, continua excessivamente regulada e excessivamente detalhada. O principio básico que fundamenta o Direito do Trabalho brasileiro em nada mudou: que os atores do cenário trabalhista são (e continuam depois de quase um século de existência como classe organizada) incapazes de negociarem por si sós, de alcançarem resultados positivos de forma cooperativa. Além disso, sem a intervenção da lei, o ambiente de trabalho seria marcado pela barbárie nas relações, onde empregadores aproveitar-se-iam de todas as possibilidades para explorar o trabalhador até a exaustão. Dado isso, pergunta-se: o objetivo inicial da CLT, que era de proteger a classe 
trabalhadora, foi alcançado? Os incentivos dos empregadores de explorar os trabalhadores foram eliminados? As leis, tão cuidadosamente desenhadas, foram capazes de criar ambientes cooperativos de trabalho? Ou o contrário aconteceu?

Um dos trabalhos pioneiros da Análise Econômica do Direito brasileiro foi realizado por Lamounier, Sadek e Castelar Pinheiro, em 2000. ${ }^{11}$ Este trabalho empírico consistia em um levantamento junto a centenas de empresas brasileiras, e tinha como objetivo coletar a avaliação e a experiência destas com relação ao funcionamento das cortes judiciais. $\mathrm{O}$ resultado mostrou que as 600 empresas participantes da pesquisa se envolveram, em um período de 10 anos, em mais de 134.500 processos (entre concluídos e em andamento na época da pesquisa). Destes, nada menos do que $80 \%$ eram processos trabalhistas. Os processos relacionados a questões comerciais e econômicas - relacionado a dívidas, quebras contratuais, problemas com fornecedores e/ou clientes, etc. aparecem bem atrás, em segundo lugar, com apenas 10,5\% de todos os casos de litígio.

Outro trabalho mais recente mostra a mesma realidade através de outra perspectiva. O Índice de Confiança do Judiciário (ICJ Brasil) é medido pela Fundação Getúlio Vargas de São Paulo, e faz levantamento junto a indivíduos residentes em sete unidades da federação (São Paulo, Rio de Janeiro, Rio Grande do Sul, Minas Gerais, Distrito Federal, Bahia e Pernambuco). ${ }^{12} \mathrm{O}$ relatório do $1^{\mathrm{o}}$ trimestre de 2013 encontrou que, das pessoas que já tiveram experiência com o Judiciário, 27\% usaram-no para resolver questões de direito do consumidor, e igualmente $27 \%$ para questões trabalhistas. Questões relacionadas à família, crime, previdência social, conflitos de trânsito e outros foram bem menos relevantes. Interessante observar que, mesmo depois de sete décadas vigorando no país, o Direito do Trabalho ainda não foi capaz de reduzir os conflitos no ambiente de trabalho, estes ainda em patamares idênticos aos das questões de Direito do Consumidor, normatizadas muito mais recentemente, nos começos dos anos 1990.

Estas pesquisas mostram que o Direito Trabalhista no Brasil, ao invés de pacificar a relação entre os participantes das relações do trabalho (empregadores e empregados), tem causado sérias distorções e incentivado o conflito. Se o objetivo de Getúlio Vargas e seus seguidores com a criação da CLT foi de alcançar um ambiente mais cooperativo de

${ }^{11}$ Cf. PINHEIRO, Armando Castelar (Org.). Judiciário e Economia no Brasil. São Paulo, SP: Ed. Sumaré, 2000.

${ }_{12}$ Os relatórios do ICJ podem ser acessados pelo site da FGVLaw. Disponível em: $<$ http://www.direitogv.com.br/>. 
relações trabalhistas e proteger os direitos dos trabalhadores no Brasil, pode-se dizer que esse objetivo não foi alcançado. A CLT e todo o conjunto de legislação trabalhista em vigor no Brasil mantêm um ambiente propício e incentivador ao litígio judicial entre as partes. Juízes, procuradores, advogados, e juristas trabalhistas argumentam de que é ainda comum o desrespeito e o abuso por parte dos empregadores. Isso certamente é verdade em muitos casos (mas não todos), mas seria mais uma evidência de que, na verdade, nem a CLT e nem a Justiça do Trabalho, da maneira como foram estruturadas há 7 décadas, têm alcançado seus objetivos. Algo está muito errado, e os números dos conflitos trabalhistas, ano após ano, só confirmam isso.

Somando-se a tudo isso, há ainda a perspectiva dos empregadores (que também são parte da relação e precisam ser analisados; afinal, sem empregadores, não há emprego, nem empregados). É amplamente conhecido o custo financeiro arcado pelas empresas quando estas decidem contratar um trabalhador formal. Este custo chega a praticamente duas vezes o valor efetivamente desembolsado pelo empregado. ${ }^{13}$ Dado o muito baixo nível de produtividade da mão de obra brasileira (devido principalmente à precária qualidade da educação brasileira, em todos os níveis) é bem pouco provável que um trabalhador de formação básica valha, atualmente, $\mathrm{R} \$ 1.900$ para sua empresa ( $\$ 1.900$ reais $=$ duas vezes o valor do salário mínimo corrente). $\mathrm{O}$ resultado disso é claro e a análise econômica já prevê: trabalhadores de baixa qualificação têm grandes dificuldades para encontrar uma posição no mercado de trabalho formal. Se relacionarmos isto ao problema crônico da baixa escolaridade média dos trabalhadores brasileiros, podemos compreender as origens da grande informalidade da economia brasileira. Discutirei um pouco mais sobre este tema na seção a seguir.

Além disso, este custo da mão de obra para o empregador no Brasil explica também o porquê das grandes cidades brasileiras terem o elevadíssimo custo de vida, entre as mais altas do planeta. No final, o consumidor (que muitas vezes também é trabalhador) é quem paga tudo.

O presente estudo não permitiria avaliar detalhadamente todos os pontos que poderiam interessar a uma Análise Econômica do Direito do Trabalho. No entanto, existem outras particularidades inerentes a este ramo do Direito brasileiro que merecem alguns breves comentários, como faremos a seguir.

${ }^{13} \mathrm{O}$ professor José Pastore, da FEA-USP, especialista em relações do trabalho, tem diversos trabalhos cujos cálculos chegam a este resultado. Disponível em: $<$ http://www.josepastore.com.br/>. 


\section{A CLT e o mercado de trabalho brasileiro: trabalhadores premium $\mathrm{x}$ trabalhadores informais ${ }^{14}$}

Lembremos o contexto histórico em que o Direito do Trabalho, materializado na Consolidação das Leis Trabalhistas, foi estabelecido no Brasil: a indústria nascente, o operariado emergente, a necessidade da estabilidade social nas cidades, o populismo de Getúlio Vargas, o seu desejo de garantir o apoio dos trabalhadores e de controlar o movimento trabalhista incipiente. Todos estes elementos foram determinantes na forma em que o direito trabalhista brasileiro tomou: paternalista, corporativista, com forte interferência estatal. ${ }^{15}$ Afora a análise política e sociológica, pode-se ainda dizer que, em termos econômicos, o conjunto de leis trabalhistas criadas por Vargas teve como consequência a criação de um clube exclusivo ou uma elite de trabalhadores. Este clube inclui aqueles amparados pelas leis formais, mas exclui todos os outros. Ou seja, existem, na verdade, dois grupos bastante distintos de trabalhadores no Brasil: os protegidos pelo clube exclusivo, a classe premium, e os nãoprotegidos, os informais ou semi-formais. As estimativas da PNAD contínua do $3^{\text {o }}$ trimestre de 2017 mostram que apenas 33,7\% dos trabalhadores são cobertos pela CLT. ${ }^{16}$ Mesmo desconsiderando os trabalhadores do setor público e os empregadores do cálculo total, ainda assim, os celetistas comporiam apenas $39,7 \%$ do total de trabalhadores. É nítido que se trata de uma elite da classe trabalhadora brasileira. $\mathrm{O}$ restante compõe-se grandemente de trabalhadores sem carteira assinada, ou trabalhadores por conta própria que, sabemos tratam-se em grande maioria de autônomos informais, com rendimento e condições de trabalho também bastante precários. Apenas uma pequena parcela

${ }^{14}$ Cf. YEUNG, Luciana. Análise Econômica do Direito do Trabalho. In: Luciano Benetti Timm (Org.). Direito e Economia no Brasil. São Paulo, SP: Atlas, 2012.

${ }^{15}$ Cf. ORGANIZAÇÃO INTERNACIONAL DO TRABALHO (OIT). Las Relaciones Laborales en Brasil: Informe RELASUR. Madrid: Ministério de Trabajo y Seguridad Social de España, 1996.

${ }^{16}$ Dos 104,26 milhões de pessoas acima de 14 anos de idade, na força de trabalho, 33,3 milhões eram empregados no setor privado com carteira de trabalho assinada, mais 29,7\% dos 6,2 milhões de trabalhadores domésticos. Descontando os empregados no setor público e os empregadores, havia um total de 88,5 milhões de trabalhadores no Brasil. Cf. INSTITUTO BRASILEITO DE GEOGRAFIA E ESTATÍSTICA (IBGE). Pesquisa Nacional por Amostra de Domicílio (PNAD). Brasília, DF: IBGE, 2017. Disponível em:

$<$ https://ww2.ibge.gov.br/home/estatistica/indicadores/trabalhoerendimento/pnad con tinua/default.shtm>. Acesso em: 18 de fevereiro de 2018. 
(menos de $5 \%$ ) dos $60 \%$ não celetistas (e não empregados no setor público) são de empregadores, que têm condições de renda superiores à da média dos celetistas.

A informalidade, além de gerar problemas na proteção legal, também leva a grandes disparidades de renda, o que pode estar colaborando com os históricos e imbatíveis índices de desigualdade no Brasil. Geralmente, trabalhadores informais têm rendimentos muito inferiores aos de suas contrapartes no mercado formal. E isso é comprovado pelas estatísticas oficiais. A mesma PNAD mencionada acima, mostra que o rendimento mensal médio dos trabalhadores com carteira assinada (setor privado), ou seja, dos trabalhadores formais, era de $\mathrm{R} \$ 2.035,00$. Isto corresponde a $62 \%$ a mais do que o rendimento médio dos trabalhadores informais, sem carteira assinada, que foi de $\mathrm{R} \$ 1.256,00$.

Por tudo isso, pode-se argumentar que o Direito do Trabalho no Brasil cria um clube exclusivo que protege os trabalhadores formais, tornando esses uma categoria premium de trabalhadores, mas exclui completamente os trabalhadores informais. Esses têm pouco ou nenhum acesso aos generosos benefícios previstos pelas leis trabalhistas oficiais.

\section{Efeitos microeconômicos}

O parágrafo $2^{\underline{0}}$ do artigo 443 da CLT assim afirma:

O contrato [de trabalho] por prazo determinado só será válido em se tratando: a) de serviço cuja natureza ou transitoriedade justifique a predeterminação do prazo;

b) de atividades empresariais de caráter transitório;

c) de contrato de experiência.

Logo em seguida o artigo 445 complementa:

O contrato de trabalho por prazo determinado não poderá ser estipulado por mais de dois anos [...].

A impossibilidade de se contratar trabalhadores temporários é um obstáculo a uma maior flexibilidade na contratação em momentos em que ela for desejada. Sabe-se que a atividade econômica tem ciclos ao longo dos meses de ano, e até mesmo ao longo dos anos. Somados a isso há os altos custos de contratação e demissão. O resultado disso é que, mesmo defrontados a uma expansão da atividade econômica, os empregadores 
hesitarão em aumentar as contratações em um primeiro momento se não estiverem certos sobre a duração desta expansão. Se contratos de trabalho temporário fossem permitidos legalmente (em um número maior de situações além daquelas identificadas pela CLT), mais trabalhadores poderiam ser contratados durante os períodos de expansão econômica, mesmo que os empregadores não tenham informação clara sobre a duração do boom inicial. Vale ainda ressaltar que leis como esta prejudicam, sobretudo, os mais jovens, que poderiam encontrar ocupações para seus períodos de férias escolares. Não é difícil de entender o porquê de o conceito de trabalho de férias para os estudantes universitários ainda ser tão pouco conhecido no Brasil, enquanto é regra para os estudantes de países europeus e norte-americanos. Se os contratos temporários fossem permitidos, mais oportunidades de trabalho poderiam ser oferecidas pelos empregadores, e os jovens trabalhadores poderiam ganhar experiência de trabalho.

Neste sentido, a reforma trabalhista de 2017, ao permitir o trabalho remoto (ou teletrabalho) e a pactuação de jornada de trabalho diferente de oito horas diárias, representam avanços significativos o que, sem dúvida alguma, irão aumentar as oportunidades de trabalho para todos aqueles que não podem se encaixar à regra padrão e tradicional de trabalho. Discutiremos sobre esse ponto mais adiante.

\section{Efeitos macroeconômicos: alta propensão a consumir, baixa propensão a poupar}

Há ainda outro conjunto de artigos da CLT que, complementados com legislações de cunho trabalhista retirados da Constituição Federal e Leis Complementares, geram fortes impactos macroeconômicos. Eles podem ser parcialmente responsáveis por algumas das deficiências macroeconômicas de longo prazo, tais como os baixos níveis de poupança doméstica (num país onde as taxas de juros estão entre as mais altas do mundo) e baixos níveis de crescimento (ou crescimento menor do que o potencial nos últimos anos). Vejamos a seguir.

A Constituição Federal de 1988 instituiu formalmente o décimo terceiro salário, e tornou-o direito a todos os trabalhadores da área urbana e rural, incluindo os trabalhadores domésticos. De acordo com alguns especialistas, o pagamento do décimo terceiro salário é uma tradição que não podia mais ser ignorada. ${ }^{17} \mathrm{O}$ racional social e cultural para a existência

${ }^{17}$ Cf. ALMEIDA, Amador Paes. CLT Comentada: Legislação, Doutrina, Jurisprudência. 2ª ed. São Paulo, SP: Saraiva, 2004. 
deste é o período de férias e de festas de fim de ano. Este salário adicional seria usado para os gastos adicionais que os trabalhadores normalmente incorrem durante os meses de dezembro e janeiro.

Os artigos 129 a 153, que formam o capítulo 4 do Título II da CLT, referem-se às férias anuais. Especificamente os artigos 142 a 145 referemse à remuneração de férias. Estes quatro artigos, somados a outros da Constituição Federal, formam o que, aos olhos de estrangeiros, constitui uma das mais peculiares regras da legislação trabalhista brasileira: o direito a um salário mais um terço durante o período das férias, quando o trabalhador não está ativo. $\mathrm{O}$ raciocínio social para esta regra é que deve-se garantir que todos os trabalhadores sejam capazes de usufruir suas férias sem comprometimento de seu salário regular, que deve ser direcionado para os gastos das atividades regulares..$^{18}$ Ou seja, há um pagamento extra para um aproveitamento extra da vida.

Finalmente, outra regra que também é uma peculiaridade da legislação brasileira é a estipulação do Fundo de Garantia por Tempo de Serviço, o FGTS. Cada trabalhador legalmente registrado tem uma conta na Caixa Econômica Federal, onde o empregador deposita, periodicamente, o valor de 1/12 de seu salário. Apesar dos recursos contidos nesta conta serem integralmente de sua propriedade, de maneira geral, a lei prevê apenas três circunstâncias (e alguns casos excepcionais) em que o trabalhador poderá sacar seu dinheiro do fundo: (i) aposentadoria, (ii) demissão sem justa causa, (iii) aquisição de casa própria. Portanto, o FGTS nada mais é do que uma poupança forçada para usos específicos, e sua existência é mais uma evidência de que o Estado brasileiro olha para seus cidadãos (no caso, os trabalhadores) como um ser irracional, incapaz de tomar decisões adequadas para si próprios, que precisam que a lei os proteja e os diga quando e quanto poupar, e quando gastar. Vale lembrar que o rendimento dos valores depositados na conta do FGTS é muito abaixo da média do mercado. Ou seja, caso o trabalhador dispusesse deste valor e decidisse de maneira autônoma aplicar este recurso em outro lugar, muito provavelmente teria um rendimento maior ao longo do tempo. Na verdade, alguns economistas chamam, de maneira mais correta, o FGTS de tributo, pois o resultado real do FGTS mais se parece a um tributo do que a um investimento (é compulsório e gera valores líquidos negativos aos indivíduos).

Estes três elementos - o décimo terceiro salário, a remuneração adicional de férias e o FGTS - são, talvez, as características mais

${ }^{18}$ Cf. ALMEIDA, Amador Paes. CLT Comentada: Legislação, Doutrina, Jurisprudência. 2ª ed. São Paulo, SP: Saraiva, 2004. 
marcantes da legislação brasileira. É pouco provável acreditar que elas possam ser eliminadas sem que haja uma convulsão nacional. Entretanto, pode-se acreditar que eles sejam parte da explicação dos baixos índices de poupança doméstica no país. Ora, em qualquer lugar, em qualquer momento da história, festas de fim de ano, férias, aposentadoria e aquisição da casa própria são as principais razões para que os trabalhadores poupem parte de suas rendas regulares. Futuros trabalhos empíricos poderiam confirmar esta hipótese, mas por ora, ela não parece ser inverossímil. Se assim for, pode-se dizer que apesar de existirem fortes incentivos econômicos para a poupança doméstica - através das altas taxas de juros, por exemplo - inexistem incentivos institucionais para que tal poupança aconteça em níveis significativos. Este pode ser o elo perdido que explicaria este paradoxo macroeconômico.

Os impactos dos baixos níveis de poupança doméstica estão fora do escopo deste trabalho, mas os economistas têm poucas dúvidas de que este seja um dos maiores obstáculos ao crescimento econômico. Não surpreende o fato de que países que observaram acelerados processos de industrialização também observaram elevadas taxas de poupança doméstica. Os Tigres Asiáticos, por exemplo, alcançavam a marca dos $35 \%$ durante os anos $1990 \mathrm{~s}^{19}$, enquanto o Brasil, mesmo nos seus melhores anos, nunca ultrapassou os $23 \%$, observando-se nos últimos anos uma taxa preocupante de cerca de $15 \%$ do PIB. ${ }^{20}$ Mais preocupante ainda é que taxas de poupança (e investimento) tem uma inércia temporal muito grande, são precisos fortes incentivos, por longos períodos de tempo, para mudar o seu patamar histórico.

Dados os limites deste trabalho, não será possível fazer uma análise econômica completa do Direito do Trabalho brasileiro, ou da CLT integral. Contudo, seria fácil listar diversos outros exemplos de como o Direito do Trabalho, e as leis trabalhistas em particular, geram impactos negativos para a economia que, no final, acabam por prejudicar os próprios trabalhadores.

${ }^{19}$ WORLD BANK. The East Asian Miracle: Economic Growth and Public Policy. New York, NY: Oxford University Press, 1993.

${ }^{20}$ AMADEO, Edward; MONTEIRO, Fernando. Crescimento Econômico e a Restrição de Poupança. In: Fábio Giambiagi; André Villela; Lavínia Barros De Castro; Jennifer Hermann (Orgs.). Economia Brasileira Contemporânea: (1945-2004). Rio de Janeiro, RJ: Elsevier, 2005, p. 284-306. 


\section{ANÁlise ECONÔMICA da ReFORMA TRABALHISTA: AlguNS PONTOS PARA ANÁLISE}

O Projeto de Lei nº 6787/2016, a chamada Reforma Trabalhista, pretende alterar uma centena de artigos da CLT, a Consolidação das Leis do Trabalho, promulgada em 1946. Impressiona o barulho feito contra ela por alguns grupos organizados, principalmente levando-se em conta a pequena dimensão dessa reforma. Vamos discutir alguns dos pontos mais polêmicos do PL 6787.

Art. 59: A duração diária do trabalho poderá ser acrescida de horas extras, em número não excedente de duas, por acordo individual, convenção coletiva ou acordo coletivo de trabalho.

Art. 59-A: Em exceção ao disposto no art. 59 desta Consolidação, é facultado às partes, mediante acordo individual escrito, convenção coletiva ou acordo coletivo de trabalho, estabelecer horário de trabalho de doze horas seguidas por trinta e seis horas ininterruptas de descanso, observados ou indenizados os intervalos para repouso e alimentação.

Art. 134, §1ํ: Desde que haja concordância do empregado, as férias poderão ser usufruídas em até três períodos, sendo que um deles não poderá ser inferior a quatorze dias corridos e os demais não poderão ser inferiores a cinco dias corridos, cada um.

Análise econômica: A justificativa econômica destes artigos é simples: os agentes são racionais, sabem o que querem ou o que é benéfico para eles. Além disso, o Teorema de Coase é claro: se as partes puderem acordar de maneira cooperativa, o resultado alcançado por elas será a melhor possível, maximiza os ganhos sociais. À lei, nestes casos, caberia garantir baixos custos de transação, ou seja, facilitar a negociação colaborativa, inclusive, reduzindo assimetrias de informação e desequilíbrios no poder de barganha. Até agora, o costume das leis trabalhistas nesses casos era de impedir a livre negociação e determinar compulsoriamente as regras do jogo (normalmente a favor do mais fraco).

Art. 75 (Regula o chamado teletrabalho, ou trabalho remoto):

Art. 75-A. A prestação de serviços pelo empregado em regime de teletrabalho observará o disposto neste Capítulo.

Art. 75-B. Considera-se teletrabalho a prestação de serviços preponderantemente fora das dependências do empregador, com a utilização de tecnologias de informação e de comunicação que, por sua natureza, não se constituam como trabalho externo. (...) 
Análise econômica: Até juristas mais ortodoxos reconhecem que o Direito anda a reboque da sociedade e das inovações tecnológicas. A regulação do teletrabalho é uma tentativa de responder a essas mudanças na organização social. Também, como visto anteriormente, a possibilidade de novas formas de trabalho aumenta as oportunidades daqueles que têm necessidades especiais. Especificamente, no das mulheres, esta medida é altamente benéfica. Historicamente - e, infelizmente - nada tem mudado recentemente: elas continuam sofrendo com poucos postos realmente adequados às necessidades da maternidade. $\mathrm{O}$ resultado tem sido claro: mulheres continuam recebendo menos, e com menos oportunidades de progressão na carreira profissional. Formas para adequar às suas necessidades, tal como o teletrabalho, deveriam ser muito benvindas por aqueles que se importam com a discriminação que tem efeitos de longo prazo.

Art. 579 (também tratado pelos artigos 545 e 578): O desconto da contribuição sindical está condicionado à autorização prévia e expressa dos que participarem de uma determinada categoria econômica ou profissional, ou de uma profissão liberal, em favor do sindicato representativo da mesma categoria ou profissão ou, inexistindo este, na conformidade do disposto no art. 591 desta Consolidação.

Art. 510-A: Nas empresas com mais de duzentos empregados, é assegurada a eleição de uma comissão para representá-los, com a finalidade de promoverlhes o entendimento direto com os empregadores.

Análise econômica: Além de violar o direito de facto da liberdade de associação, a contribuição sindical obrigatória, dentro de um contexto de unicidade sindical como a existente no Brasil, é uma afronta à liberdade econômica individual, uma extorsão dentro de um contexto de monopólio garantido por lei. A análise econômica iria além: além da contribuição obrigatória, a unicidade sindical também deveria ser extinta.

Com relação ao artigo 510, aí reside o maior potencial para evolução nas relações trabalhistas brasileiras. As comissões são comuns em países com tradição de cooperação capital-trabalho, como na Alemanha. Empregados entendem mais sobre os desafios e oportunidades existentes em seus respectivos locais de trabalho do que sindicalistas alienígenas à empresa. Empregadores também sentem-se mais à vontade para discutir e negociar com seus próprios colaboradores. Mesmo que o Brasil tenha ainda um longo caminho até chegar ao ponto das comissões alemãs (e outras similares), essa previsão pelo PL é muito bem-vinda. 
Art. 611-A: A convenção coletiva e o acordo coletivo de trabalho têm prevalência sobre a lei quando, entre outros, dispuserem sobre:

I - pacto quanto à jornada de trabalho, observados os limites constitucionais;

II - banco de horas anual;

III - intervalo intrajornada, respeitado o limite mínimo de trinta minutos para jornadas superiores a seis horas;

IV - adesão ao Programa Seguro-Emprego (PSE), de que trata a Lei no 13.189 , de 19 de novembro de 2015;

$\mathrm{V}$ - plano de cargos, salários e funções compatíveis com a condição pessoal do empregado, bem como identificação dos cargos que se enquadram como funções de confiança;

VI - regulamento empresarial;

VII - representante dos trabalhadores no local de trabalho;

VIII - teletrabalho, regime de sobreaviso, e trabalho intermitente;

IX - remuneração por produtividade, incluídas as gorjetas percebidas pelo empregado, e remuneração por desempenho individual;

$\mathrm{X}$ - modalidade de registro de jornada de trabalho;

XI - troca do dia de feriado;

XII - enquadramento do grau de insalubridade;

XIII - prorrogação de jornada em ambientes insalubres, sem licença prévia das autoridades competentes do Ministério do Trabalho;

XIV - prêmios de incentivo em bens ou serviços, eventualmente concedidos em programas de incentivo;

XV - participação nos lucros ou resultados da empresa.

Análise econômica: Este é um dos pontos mais polêmicos do projeto. No entanto, trata-se de muito barulho por pouca coisa, sem contar que é solidamente embasada na análise econômica, sobretudo no conceito de agentes racionais e no Teorema de Coase: os trabalhadores sabem o que é melhor para eles e, quando garantidas as condições mínimas para negociação, o resultado será o mais eficiente. Isso será sobretudo mais certo se a negociação for feita via comissões de representantes, quando é possível melhor equiparar poderes de barganha. É muito barulho por pouco, porque o artigo 611-A elenca quinze temas (e somente quinze) que podem ser tratados por convenções e acordos coletivos; em seguida, $\mathrm{O}$ artigo 611-B lista trinta assuntos que não podem ser negociados:

Art. 611-B. Constituem objeto ilícito de convenção coletiva ou de acordo coletivo de trabalho, exclusivamente, a supressão ou a redução dos seguintes direitos: 
I - normas de identificação profissional, inclusive as anotações na Carteira de Trabalho e Previdência Social;

II - seguro-desemprego, em caso de desemprego involuntário;

III - valor dos depósitos mensais e da indenização rescisória do Fundo de Garantia do Tempo de Serviço (FGTS);

IV - salário mínimo;

V - valor nominal do décimo terceiro salário;

VI - remuneração do trabalho noturno superior à do diurno;

VII - proteção do salário na forma da lei, constituindo crime sua retenção dolosa;

VIII - salário-família;

IX - repouso semanal remunerado;

$X$ - remuneração do serviço extraordinário superior, no mínimo, em 50\% (cinquenta por cento) à do normal;

XI - número de dias de férias devidas ao empregado;

XII - gozo de férias anuais remuneradas com, pelo menos, um terço a mais do que o salário normal;

XIII - licença-maternidade com a duração mínima de cento e vinte dias;

XIV - licença-paternidade nos termos fixados em lei;

XV - proteção do mercado de trabalho da mulher, mediante incentivos específicos, nos termos da lei;

XVI - aviso prévio proporcional ao tempo de serviço, sendo no mínimo de trinta dias, nos termos da lei;

XVII - normas de saúde, higiene e segurança do trabalho previstas em lei ou em normas regulamentadoras do Ministério do Trabalho;

XVIII - adicional de remuneração para as atividades penosas, insalubres ou perigosas;

XIX - aposentadoria;

$X X$ - seguro contra acidentes de trabalho, a cargo do empregador;

XXI - ação, quanto aos créditos resultantes das relações de trabalho, com prazo prescricional de cinco anos para os trabalhadores urbanos e rurais, até o limite de dois anos após a extinção do contrato de trabalho;

XXII - proibição de qualquer discriminação no tocante a salário e critérios de admissão do trabalhador com deficiência;

XXIII - proibição de trabalho noturno, perigoso ou insalubre a menores de dezoito anos e de qualquer trabalho a menores de dezesseis anos, salvo na condição de aprendiz, a partir de quatorze anos;

XXIV - medidas de proteção legal de crianças e adolescentes;

XXV - igualdade de direitos entre o trabalhador com vínculo empregatício permanente e o trabalhador avulso; 
XXVI - liberdade de associação profissional ou sindical do trabalhador, inclusive o direito de não sofrer, sem sua expressa e prévia anuência, qualquer cobrança ou desconto salarial estabelecidos em convenção coletiva ou acordo coletivo de trabalho;

XXVII - direito de greve, competindo aos trabalhadores decidir sobre a oportunidade de exercê-lo e sobre os interesses que devam por meio dele defender;

XXVIII - definição legal sobre os serviços ou atividades essenciais e disposições legais sobre o atendimento das necessidades inadiáveis da comunidade em caso de greve;

XXIX - tributos e outros créditos de terceiros;

XXX - as disposições previstas nos arts. 373-A, 390, 392, 392-A, 394, 394-A, 395, 396 e 400 desta Consolidação.

A não possibilidade de negociação também pode ser explicada economicamente. Tratam-se justamente de diversos casos de externalidades e outras falhas de mercado que, como discutimos acima, são situações que precisam de uma regulação mais presente, por exemplo, em casos envolvendo questões de saúde, segurança, insalubridade, etc. Por terem potencial de criar custos não previstos ou não incoporados pelas empregadoras, o Estado precisa, nesses casos, garantir que o menor dano seja gerado para os trabalhadores e para a sociedade como um todo.

\section{CONCLUSÕES}

O Direito do Trabalho brasileiro, muito embasado na Consolidação das Leis do Trabalho (CLT) da década de 1940, está ultrapassado e inadequado para a realidade do Brasil e do mundo atual. Os objetivos dos formuladores originais da CLT - proteção ao trabalhador brasileiro, redução da exploração pelos empregadores - não estão sendo alcançados, pois mais da metade da população trabalhadora é excluída do mercado de trabalho formal. Também não foi alcançado o objetivo de criar um ambiente de cooperação e redução de conflitos entre as partes ou mesmo de exploração, dado os ainda altíssimos níveis de litigância (os maiores do Judiciário brasileiro, em termos de matéria geral). Além disso, os benefícios trabalhistas garantidos pela CLT e demais leis estão criando distorções macroeconômicas e microeconômicas inicialmente não previstos. 
Além disso, o Direito em geral, e o Direito do Trabalho, em particular, poderiam estar mais abertos a novas formas de pesquisa e compreensão da realidade. Metodologias empíricas são formas simples de observação da realidade, que podem trazer valiosas evidências de como as leis impactam as pessoas e quais os resultados por elas gerados, se satisfatórias ou não, aos olhos de quem as criaram inicialmente. Com base nas observações empíricas seria possível fazer previsões de comportamentos dos diversos agentes da sociedade. É crucial e urgente que mais trabalhos de análise de dados, como aqueles empregados pela Análise Econômica, venham dar suporte ao Direito do Trabalho para que ele possa se modernizar de forma a melhor atender aos verdadeiros anseios dos participantes das relações trabalhistas no Brasil.

Para concluir, ressalte-se que, de um prisma econômico, a Reforma Trabalhista de 2017 é tímida, garantindo o óbvio e indo aquém do que seria ideal. As novas tecnologias do big data, das impressoras 3-D, das máquinas inteligentes, da robotização ilimitada, etc. virão como verdadeiros tsunamis, varrendo o mundo do trabalho como o conhecemos, pressionando a todos nós - sem exceção - a repensarmos o papel do trabalho humano, das relações do trabalho e das normas trabalhistas. É urgente o Direito do Trabalho, no Brasil e no mundo, voltar-se a essas questões que, sem dúvida, serão muito mais impactantes nas vidas dos trabalhadores em um futuro bastante próximo.

\section{REFERÊNCIAS}

ALMEIDA, Amador Paes. CLT Comentada: Legislação, Doutrina, Jurisprudência. 2ª ed. São Paulo, SP: Saraiva, 2004.

AMADEO, Edward; MONTEIRO, Fernando. Crescimento Econômico e a Restrição de Poupança. In: Fábio Giambiagi; André Villela; Lavínia Barros De Castro; Jennifer Hermann (Orgs.). Economia Brasileira Contemporânea: (1945-2004). Rio de Janeiro, RJ: Elsevier, 2005.

COASE, Ronald. The Problem of Social Cost. Journal of Law and Economics, Vol. 3, 1, 1960. 
FRIEDMAN, David. Law's Order: What Economics has to do with Law and why it Matters. Princeton, NJ: Princeton University Press, 2001.

INSTITUTO BRASILEITO DE GEOGRAFIA E ESTATÍSTICA (IBGE). Pesquisa Nacional por Amostra de Domicílio (PNAD). Brasília, DF: IBGE, 2017. Disponível em: $<$ https://ww2.ibge.gov.br/home/estatistica/indicadores/trabalhoerendim ento/pnad continua/default.shtm>. Acesso em: 18 de fevereiro de 2018.

MANKIW, Gregory. Princípios de Microeconomia. $6^{a}$ ed. Trad. Allan Vidigal Hastings; Elisete Paes Lima; Ez2 Translate. São Paulo, SP: Cengage Learning, 2014.

MAS-COLELL, Andreu; WHINSTON, Michael; GREEN, Jerry. Microeconomic Theory. New York, NY: Oxford University Press, 1995.

McCLOSKEY, Deirdre. Others Things Equal: The so-called Coase Theorem. Eastern Economic Journal, Vol. 24, 3, 1998.

PINHEIRO, Armando Castelar (Org.). Judiciário e Economia no Brasil. São Paulo, SP: Ed. Sumaré, 2000.

POPPER, Karl. A Lógica da Pesquisa Científica. 11 $1^{a}$ ed. Trad. Leonidas Hegenberg; Octanny Silveira da Mota. São Paulo, SP: Editora Cultrix, 2004.

ORGANIZAÇÃO INTERNACIONAL DO TRABALHO (OIT). Las Relaciones Laborales en Brasil: Informe RELASUR. Madrid: Ministério de Trabajo y Seguridad Social de España, 1996.

RICARDO, David. Princípios de Economia Política e Tributação. Trad. Paulo Henrique Ribeiro Sandroni. São Paulo, SP: Nova Cultural, 1996. 
SMITH, Adam. A Riqueza das Nações: Investigação sobre sua

Natureza e suas Causas, Volume I. Trad. Luiz João Baraúna. São Paulo, SP: Nova Cultural, 1996.

WORLD BANK. The East Asian Miracle: Economic Growth and Public Policy. New York, NY: Oxford University Press, 1993.

YEUNG, Luciana. Economic Analysis of Labor Law. In: Alain Marciano; Giovanni Battista Ramello (eds.). Encyclopedia of Law and Economics. New York, NY: Springer, 2017.

Análise Econômica do Direito do Trabalho. In: Luciano Benetti

Timm (Org.). Direito e Economia no Brasil. São Paulo, SP: Atlas, 2012.

Análise Econômica do Direito do Trabalho e da Reforma Trabalhista (Lei no 13.467/17)

Economic Analysis of Labor Law and Labor Reform (Act No. 13.467/17)

Submetido em: 2017-11-27

Aceito em: 2018-01-30 